\title{
ANÁLISE DO EFEITO DA ADIÇÃO DE FIBRAS DE POLIPROPILENO NAS PROPRIEDADES MECÂNICAS DO CONCRETO
}

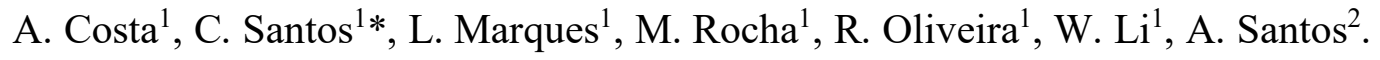 \\ *Autor de Contato: carlosrochacrhs@gmail.com \\ ${ }^{1}$ Alunos do curso de Engenharia Civil na Pontifícia Universidade Católica de Minas Gerais, Belo Horizonte, Brasil. \\ ${ }^{2}$ Professor Dr. do curso de Engenharia Civil na Pontifícia Universidade Católica de Minas Gerais, Belo Horizonte, \\ Brasil.
}

\section{RESUMO}

O concreto reforçado com fibras (CRF) apresenta propriedades que devem ser observadas para a aplicação do material na construção civil. Este trabalho tem por objetivo apresentar uma revisão bibliográfica da adição de fibras de polipropileno nos compósitos de concreto, abordando a preparação, moldagem e análise dos resultados técnicos desta fibra em referência a uma amostra padrão sem incorporação de fibras. Além disso, foi realizado um estudo experimental avaliando a capacidade mecânica do CRF, levando em consideração os ensaios de compressão axial e compressão diametral. Dessa forma, foi possível concluir que a adição de fibra altera algumas propriedades do concreto, mas, com limitações a determinadas utilizações na construção civil. Contudo através do estudo aqui abordado foi possível obter parâmetros e conceitos que serviram como base para futuras aplicações.

Palavras chave: Concreto Com Fibras, Fibras de Polipropileno, Propriedades Mecânicas.

\section{RESUMEN}

El hormigón reforzado con fibras (CRF) presenta propiedades que deben ser observadas para la aplicación del material en la construcción civil. Este trabajo tiene como objetivo presentar una revisión bibliográfica de la adición de fibras de polipropileno en los compuestos de hormigón, abordando la preparación, el moldeo y el análisis de los resultados técnicos de esta fibra en referencia a un padrón de la muestra sin incorporación de fibras. Además, se realizó un estudio experimental en el que se evaluó la capacidad mecánica del CRF, teniendo en cuenta los ensayos de compresión axial y compresión diametral. Así, se pudo concluir que la adición de fibra cambia algunas propiedades del hormigón, pero con limitaciones a ciertos usos en la construcción civil. Sin embargo, a través de este estudio fue posible obtener parámetros y conceptos que sirven de base para futuras aplicaciones.

Palabras clave: hormigón con fibras, fibras de polipropileno, propiedades mecánicas.

\begin{abstract}
Fiber reinforced concrete (CRF) has properties that must be observed for the application of the material in civil construction. This work aims to present a bibliographical review of the addition of polypropylene fibers in concrete composites, approaching the preparation, molding and analysis of the technical results of this fiber in reference to a standard sample without fiber incorporation.
\end{abstract}


In addition, an experimental study was carried out evaluating the mechanical capacity of the CRF, taking into account the axial compression and diametrical compression tests. Thus, it was possible to conclude that the addition of fiber alters some properties of concrete, but with limitations for certain uses in civil construction. However, through the study discussed here, it was possible to obtain parameters and concepts that served as a basis for future applications.

Keywords: Fiber Concrete, Polypropylene Fibers, Mechanical Properties.

\section{INTRODUÇÃO}

O concreto reforçado com fibras (CRF) é um material composto por fibras que são uniformemente distribuídas e orientadas aleatoriamente. As fibras incluem fibras de aço, fibras de vidro, fibras sintéticas e fibras naturais. O comportamento do CRF muda conforme as propriedades da fibra adotada, tal como: geometria, distribuição, orientação e densidade.

Segundo Medeiros (2012), a utilização de fibras em concreto surgiu em 1911 com Grahan, quando ele propôs o uso de fibras de aço junto com a armadura, para obter-se um aumento na resistência do concreto armado. Portanto, a partir dos anos 60 que se intensificaram as pesquisas e os estudos, que foram capazes de desenvolver um material com ótimas propriedades e ampla aplicabilidade em obras. Mesmo com esses estudos não chegaram a um concreto sem fissuras, assim foram desenvolvidos diferentes tipos de fibras, para aperfeiçoar o concreto dependendo da finalidade e do local de aplicação.

Para Figueiredo (2011), a eficácia da fibra está relacionada ao seu desempenho como ponte de transferência de tensão na fissura do concreto. $\mathrm{O}$ teor de fibras adicionadas a mistura, exerce forte influência sobre a capacidade de reforço da mesma. Portanto, quanto maior for o teor adotado, maior será o número de fibras desempenhando a função de ponte de transferência de tensão, aumentando assim, o reforço pós fissuração do concreto. Além do teor, outras propriedades como geometria e resistência das fibras, influenciam no seu desempenho pós fissuração.

Neste sentido, é relevante o estudo da influência da adição de fibras de polipropileno nas propriedades mecânicas do concreto, uma vez que o seu excesso pode causar alterações significativas nas características mecânicas importantes do concreto.

\section{METODOLOGIA}

Para estruturar todo o escopo do presente trabalho inicialmente foi definido as principais etapas de toda a pesquisa, bem como as características de cada uma delas. Após a definição, foi elaborado um fluxograma, conforme apresentado na Figura 1. 


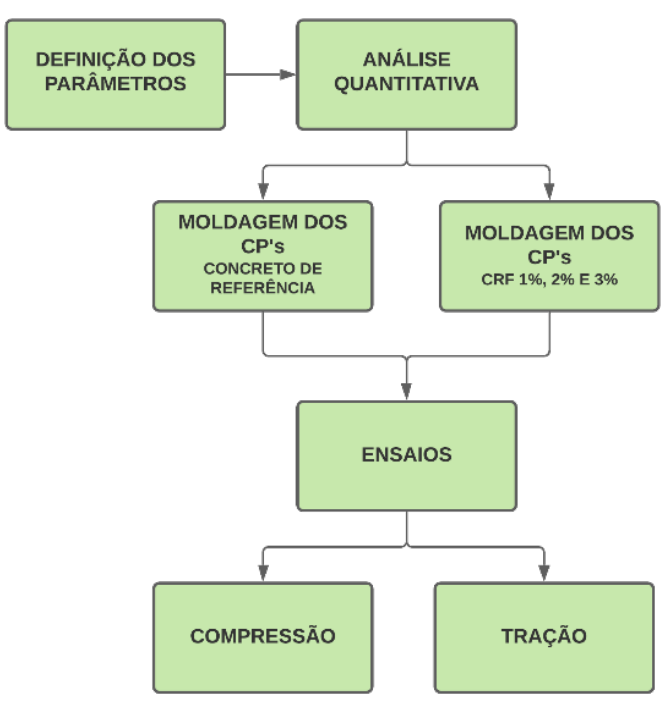

Figura 1 - Fluxograma das Etapas da Pesquisa

\subsection{Definição Dos Parâmetros}

Após a realização de todo o estudo teórico, foi necessário analisar quais as variáveis e parâmetros que seriam essenciais ao estudo, de modo a abranger as características e comportamentos do concreto.

Inicialmente definiu-se as variáveis de análise ligadas as características do concreto:

- Tipo de concreto: Optou-se por utilizar o concreto auto adensável, uma vez que são inúmeras as suas aplicações e funcionalidades;

- Cimento utilizado - CP-V ARI 50MPa: Devido ao alto ganho de resistência do período de 24 horas este tipo de cimento tem uma ampla aplicabilidade. Por este motivo optou-se por este tipo.

- Agregado graúdo - Brita 0 (gnaisse; $\emptyset \max =12,5 \mathrm{~mm} ; d=1,2 / \mathrm{cm}^{3}$ ): Por se tratar de concreto auto adensável, quanto maior a trabalhabilidade melhor. Por este motivo foi escolhido como agregado graúdo a brita 0 , uma vez que ela apresenta um diâmetro máximo pequeno com relação aos demais agregados. E quanto menor o agregado, maior a trabalhabilidade.

- Agregado Miúdo - Areia média: A escolha deste material se deu exclusivamente pela disponibilidade do mesmo nos laboratórios.

Em um segundo momento analisou-se as características da fibra a ser utilizada:

- Material - Polipropileno: Foi analisado e optou-se pela utilização dessa fibra devido a sua flexibilidade e baixa densidade, o que resultaria em um decréscimo de peso no concreto.

- Forma - Ondulada: O formato ondulado irá garantir a fibra uma maior aderência ao concreto.

- Comprimento - 45mm: Como era desejável manter a trabalhabilidade do concreto, optou-se por uma fibra menor.

Por fim, após analisar as características de ambos os materiais tais informações foram organizadas, conforme apresentado na Tabela 1. 
Tabela 1 - Parâmetros Analisados

\begin{tabular}{|c|c|c|c|}
\cline { 2 - 4 } \multicolumn{1}{c|}{} & $\begin{array}{c}\text { VARIÁVEIS DE } \\
\text { ANÁLISE }\end{array}$ & TIPOS & DESCRIÇÃO \\
\hline \multirow{4}{*}{ CONCRETO } & Concreto & 1 & $\begin{array}{c}\text { Concreto Auto } \\
\text { Adensável }\end{array}$ \\
\cline { 2 - 4 } & Cimento & 1 & CP V ARI - 50MPa \\
\cline { 2 - 4 } & Agregado Graúdo & 1 & Brita 0 \\
\cline { 2 - 4 } & Agregado Miúdo & 1 & Areia Média \\
\hline \multirow{3}{*}{ FIBRA } & Material & 1 & Polipropileno \\
\cline { 2 - 4 } & Forma & 1 & Ondulada \\
\cline { 2 - 4 } & Comprimento & 1 & $45 \mathrm{~mm}$ \\
\hline
\end{tabular}

\subsection{Análise Quantitativa}

A partir de análises do comportamento do concreto e pesquisas práticas já realizadas, foi definido a realização dos ensaios de compressão axial e compressão diametral. Para tanto foram confeccionados 15 corpos de prova, sendo 7 utilizados para determinação da resistência a tração indireta e 8 utilizados para a determinação da resistência à compressão. Vale ressaltar que a quantidade de corpos de prova apresentada acima é referente a cada tipo de concreto analisado (concreto de Referência e concreto com adição de fibras).

\subsection{Concreto de Referência}

O traço para o concreto de referência foi obtido inicialmente através de pesquisas em normas, artigos e monografias. Após realizar algumas correções necessárias, foram obtidas as seguintes relações apresentadas na Tabela 2.

Tabela 2 - Traço de Referência

\begin{tabular}{|c|c|}
\hline Material & $\begin{array}{c}\text { Relação } \mathbf{~ e m} \\
\text { Massa } \mathbf{~ k g} / \mathbf{m}^{\mathbf{3}}\end{array}$ \\
\hline $\begin{array}{c}\text { Cimento Portland } \\
\text { CPV }\end{array}$ & 1,00 \\
\hline Agregado Miúdo & 1,57 \\
\hline Agregado Graúdo & 2,19 \\
\hline Ś́lica & 0,08 \\
\hline Aditivo & 0,012 \\
\hline Água & 0,38 \\
\hline
\end{tabular}

A partir das orientações apresentadas na NBR 5738:, definiu-se que seria realizado a confecção inicial de $12 \mathrm{CP}$ 's de concreto de $10 \times 20 \mathrm{~cm}$. Posteriormente, com a relação em massa e a quantidade de corpos de prova definidos, determinou-se a quantidade necessária (em kg) de cada material, considerando $20 \%$ de perdas e aplicando um fator de correção em massa de $25 \%$, uma vez que inicialmente era para ser moldados 15 CP's. O resultado está apresentado na Tabela 3. 
Tabela 2 - Concreto de Referência

\begin{tabular}{|c|c|c|c|c|c|}
\hline \multicolumn{6}{|c|}{ TRAÇO CONCRETAGEM - CP's 10x20 } \\
\hline & & & & Massa kg & Massa kg \\
\hline Material & $\begin{array}{c}\text { Volume CP's } \\
\text { m }^{3} 15 \mathrm{CP}^{\prime} \text { 's }\end{array}$ & $\begin{array}{c}\text { Relação } \\
\text { em Massa }\end{array}$ & $\begin{array}{l}\text { Quantidade } \\
\mathrm{kg} / \mathrm{m}^{3}\end{array}$ & $\begin{array}{c}\text { Fator De } \\
\text { Perda } \\
\mathbf{2 0 \%}\end{array}$ & $\begin{array}{c}\text { Fator De } \\
\text { Correção } \\
25 \%\end{array}$ \\
\hline $\begin{array}{c}\text { Cimento Portland } \\
\text { CPV }\end{array}$ & \multirow{6}{*}{0.0236} & 1.00 & 460 & 13.01 & 16.26 \\
\hline Agregado Miúdo & & 1.57 & 722 & 20.41 & 25.52 \\
\hline Agregado Graúdo & & 2.19 & 1007 & 28.47 & 35.59 \\
\hline Sílica Ativa & & 0.08 & 36.8 & 1.04 & 1.30 \\
\hline Aditivo & & 0.012 & 5.52 & 0.16 & 0.20 \\
\hline Água & & 0.32 & 147 & 4.16 & 5.20 \\
\hline
\end{tabular}

A partir das informações citadas na Tabela 3, produziu-se o concreto de referência. Após a concretagem foi realizado o teste de de Slump descrito em NM 67:96, afim de analisar se a trabalhabilidade do concreto estava dentro dos limites estabelecidos na norma.

Posteriormente os corpos de prova foram moldados conforme a NBR 5738:2015. Após a moldagem, os corpos de prova foram armazenados em uma câmara fria até passarem pelo processo de desforma e atingirem a cura referente a 7 e 28 dias. Nas referentes datas os CP's foram ensaiados.

\subsection{Traços Com Adição De Fibras}

Para a pesquisa foi proposto a adição de fibras ao concreto utilizando os percentuais de $1 \%, 2 \%$ e $3 \%$. A definição destes percentuais baseou-se na especificação do fornecedor da fibra que indicava um valor máximo de $2 \%$. Definido isto, partiu-se da utilização do traço utilizado na moldagem dos corpos de prova do concreto de referência apresentado anteriormente na Tabela 3.

A Tabela 4 apresenta os traços para os percentuais de fibra utilizados.

Tabela 3 - Quantitativo de Materiais

\begin{tabular}{|c|c|c|c|c|c|}
\hline \multicolumn{6}{|c|}{ TRAÇO CONCRETAGEM - CP's 10x20 } \\
\hline & & & & Massa kg & Massa kg \\
\hline Material & $\begin{array}{l}\text { Volume CP's } \\
\text { m }^{3} 15 \mathrm{CP}^{\prime} \mathrm{s}\end{array}$ & $\begin{array}{c}\text { Relação } \\
\text { em Massa }\end{array}$ & $\begin{array}{c}\text { Quantidade } \\
\mathrm{kg} / \mathrm{m}^{3}\end{array}$ & $\begin{array}{c}\text { Fator De } \\
\text { Perda } \\
\mathbf{2 0 \%}\end{array}$ & $\begin{array}{c}\text { Fator De } \\
\text { Correção } \\
25 \%\end{array}$ \\
\hline $\begin{array}{c}\text { Cimento Portland } \\
\text { CPV }\end{array}$ & \multirow{6}{*}{0.0236} & 1.00 & 460 & 13.01 & 16.26 \\
\hline Agregado Miúdo & & 1.57 & 722 & 20.41 & 25.52 \\
\hline Agregado Graúdo & & 2.19 & 1007 & 28.47 & 35.59 \\
\hline Sílica Ativa & & 0.08 & 36.8 & 1.04 & 1.30 \\
\hline Aditivo & & 0.012 & 5.52 & 0.16 & 0.20 \\
\hline Água & & 0.32 & 147 & 4.16 & 5.20 \\
\hline $\begin{array}{c}\text { Fibra Polipropileno } \\
1 \%\end{array}$ & 0.0002 & 0.02 & 8.90 & 0.25 & 0.31 \\
\hline
\end{tabular}




\begin{tabular}{|c|c|c|c|c|c|}
\hline $\begin{array}{c}\text { Fibra Polipropileno } \\
\mathbf{2} \%\end{array}$ & 0.0005 & 0.04 & 17.80 & 0.50 & 0.63 \\
\hline $\begin{array}{c}\text { Fibra Polipropileno } \\
\mathbf{3} \%\end{array}$ & 0.0007 & 0.06 & 27.11 & 0.77 & 0.96 \\
\hline
\end{tabular}

$\mathrm{Na}$ sequência foi efetuado as três concretagens considerando a adição de $1 \%, 2 \%$ e $3 \%$ de fibra de polipropileno a partir da massa total de cimento.

Para as três concretagens utilizando fibras foi adotado os mesmos procedimentos da concretagem e ensaios realizados para o concreto de referência, visando manter as condições as mais similares possível.

\section{RESULTADOS}

A partir dos resultados mecânicos obtidos, realizou-se uma análise qualitativa e comparativa entre os diferentes corpos de prova, conforme apresentado na sequência.

\subsection{Análise Qualitativa Dos Traços}

Os traços executados apresentaram características visuais um pouco diferentes. Inicialmente o traço de referência executado, apresentou um bom espalhamento. Já nos demais traços que tiveram adição de fibra percebeu-se uma menor plasticidade do concreto, ocorrendo uma maior segregação do concreto conforme mostrado na Figura 2.
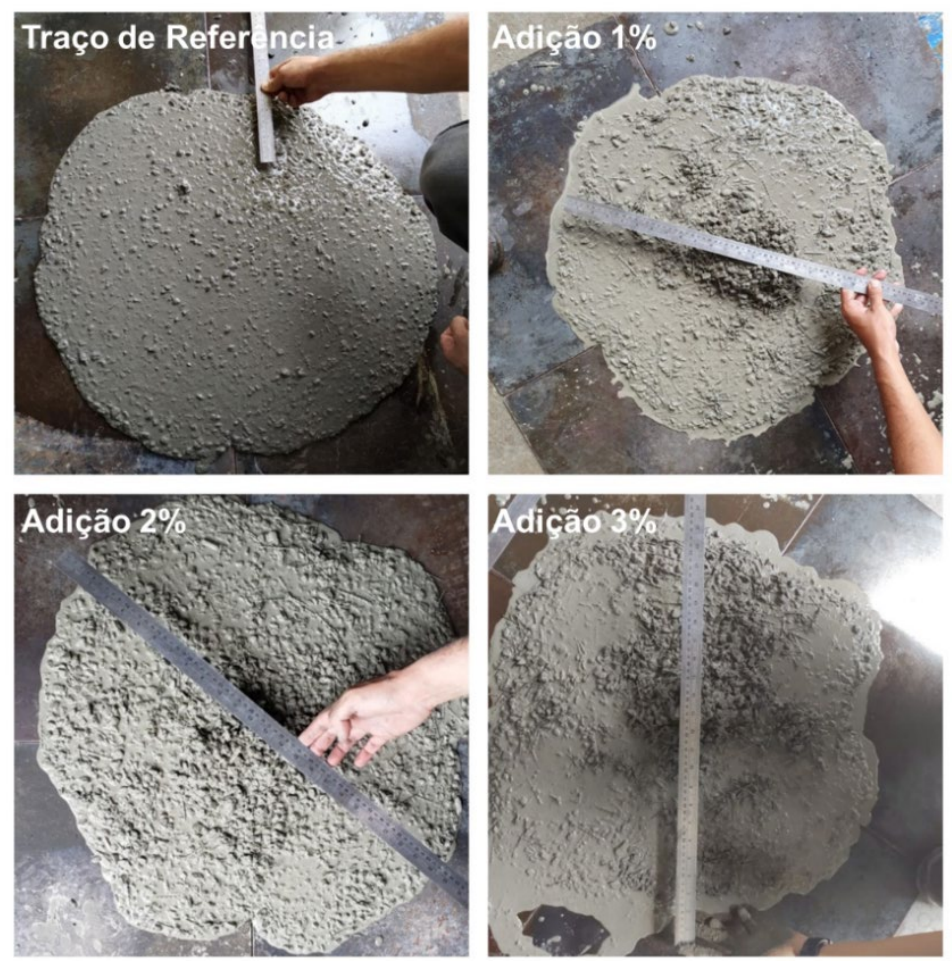

Figura 2 - Slump test para os quatro traços realizados

Avaliando as condições externas de temperatura e umidade, constata-se que não houve grandes variações, uma vez que os traços utilizando fibras foram executados com diferenças de poucos dias. Com isso, acredita-se que essa segregação do concreto ocorreu em função da característica da 
fibra de polipropileno que tende a diminuir a viscosidade do compósito. Essa segregação aumentou com o incremento do teor de fibras.

Esse fato pode ser justificado em função da maior interação e maior compacidade com a adição de fibras que diminui a fluidez do compósito.

Na Figura 3 à Figura 6 é possível avaliar o acabamento de diferentes amostras após a desmoldagem.

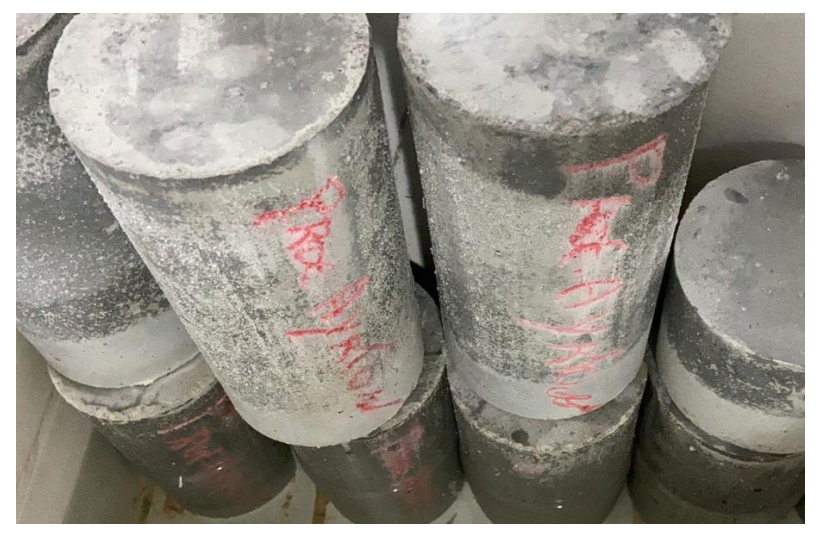

Figura 3 - Acabamento de diferentes amostras após a desforma - Concreto Referência

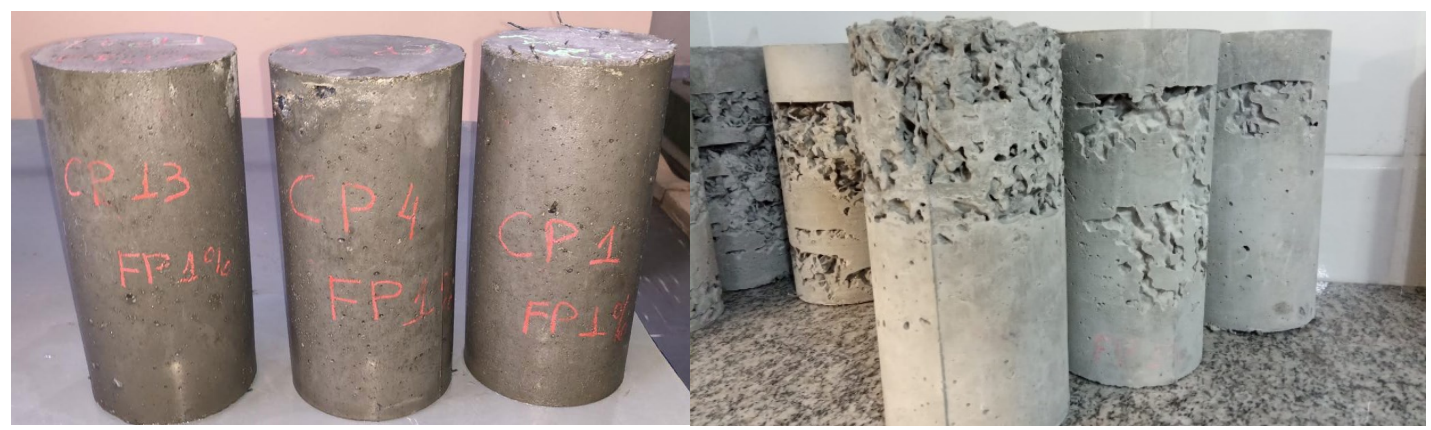

Figura 4 - Acabamento de diferentes amostras após a desforma - Adição 1\%

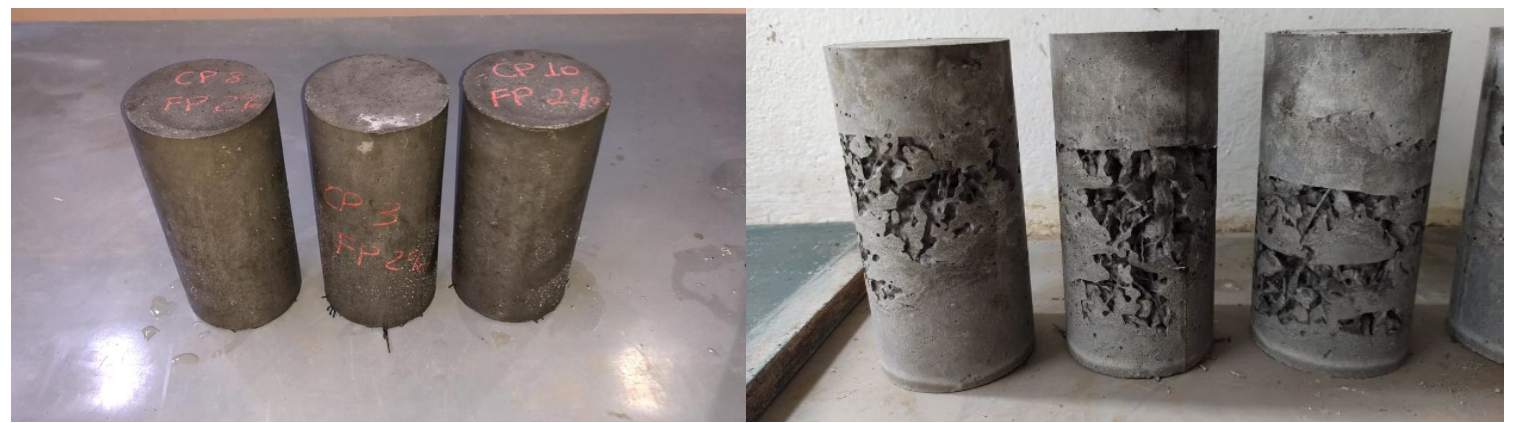

Figura 5 - Acabamento de diferentes amostras após a desforma - Adição 2\% 


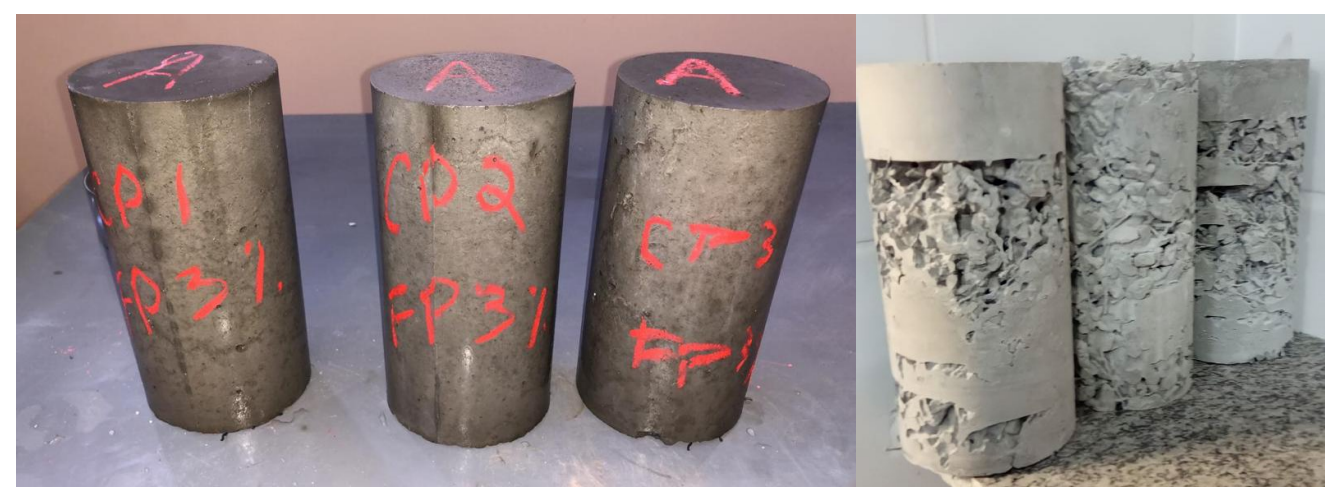

Figura 6 - Acabamento de diferentes amostras após a desforma - Adição 3\%

Conforme apresentado na Figura 3 à Figura 6, os corpos de prova do traço com 3\% de adição de fibra tiveram um pior acabamento externo, tendo grande quantidade de falhas e grandes volumes de vazios em determinados pontos. Tal característica pode ter sido ocasionada devido à presença de uma alta densidade de fibras nas regiões mais críticas. Como o concreto utilizado é um concreto autoadensável, não foi utilizado qualquer tipo de vibração externa, para acabamento dos corpos de prova.

Outra observação qualitativa feita durante o processo de concretagem foi que os corpos de prova com adição de fibra após o $12^{\circ} \mathrm{CP}$ o concreto apresentou características típicas do início de pega, com o endurecimento e retenção de água. Isso pode ter corroborado para as falhas citadas anteriormente.

\subsection{Compressão Axial}

A partir dos ensaios de compressão axial realizados nos corpos de prova dos 4 traços elaborados, foi realizada a análise estatística.

Para isso calculou-se a média para definir como grandeza equidistante dos extremos das outras amostras. Em seguida definiu-se o valor do desvio padrão para expressar o grau de dispersão da amostra estudada, tornando-se possível obter os limites inferiores e superiores para cada faixa de amostragem.

A partir destes limites calculou-se uma nova média utilizando apenas os resultados contidos dentro do intervalo, ou seja, obteve-se a dispersão e/ou variação que mostra o quão distante cada valor desse conjunto está dos resultados de referência. Essa abordagem foi realizada conforme prescreve a ABNT.

Ademais, foi elaborada uma análise global desses resultados separadamente para cada tipo de ensaio e o tempo em dias em que foi realizado, como demonstrado na Tabela 5.

Tabela 4 - Resistência a Compressão aos 7 dias

\begin{tabular}{|c|c|c|c|c|c|c|c|c|c|}
\hline \multicolumn{8}{|c|}{ COMPRSSÃO AXIAL - 7 DIAS } \\
\hline & \multicolumn{2}{|c|}{ RESISTÊNCIA (Mpa) } & MÉDIA & $\begin{array}{c}\text { DESVIO } \\
\text { PADRÃO }\end{array}$ & LIM SUP & LIM INF MED COP & $\begin{array}{c}\text { DIFERENÇA } \\
\text { PERCENTUAL }\end{array}$ \\
\hline $\begin{array}{c}\text { TRAÇO DE } \\
\text { REFERÊNCIA }\end{array}$ & 46,47 & 74,51 & 65,18 & 65,18 & 10,39 & 75,57 & 54,79 & 69,85 & \\
\hline $\mathbf{1 \%}$ & 42,76 & 43,17 & 33,89 & 42,76 & 4,03 & 46,79 & 38,73 & 42,97 & $38 \%$ \\
\hline $\mathbf{2} \%$ & 48,85 & 44,26 & 43,27 & 44,26 & 2,26 & 46,52 & 42,00 & 43,77 & $37 \%$ \\
\hline $\mathbf{3 \%}$ & 46,32 & 41,42 & 41,26 & 41,42 & 2,21 & 43,63 & 39,21 & 41,34 & $41 \%$ \\
\hline
\end{tabular}


Por meio dos resultados obtidos no ensaio, verificou-se que os concretos dos CP's com adição de fibras tiveram uma queda na resistência à compressão axial em relação ao traço de referência. Para o ensaio de compressão axial aos 7 dias obteve-se para o concreto com as diferentes frações volumétricas de fibras de polipropileno uma diferença percentual na resistência de:

- Diferença Percentual de 38\%: Baixa fração volumétrica (1\%);

- Diferença Percentual de 37\%: Moderada Fração Volumétrica (2\%);

- Diferença Percentual de 41\%: Alta Fração Volumétrica (3\%).

Através de uma análise global dos dados obtidos, foi elaborado o gráfico apresentado na Figura 7 , tornando possível fazer um comparativo entre as resistências com relação ao traço de referência e para as diferentes frações volumétricas de fibras de polipropileno incorporadas ao concreto, usando os dados apresentados na Tabela 5.

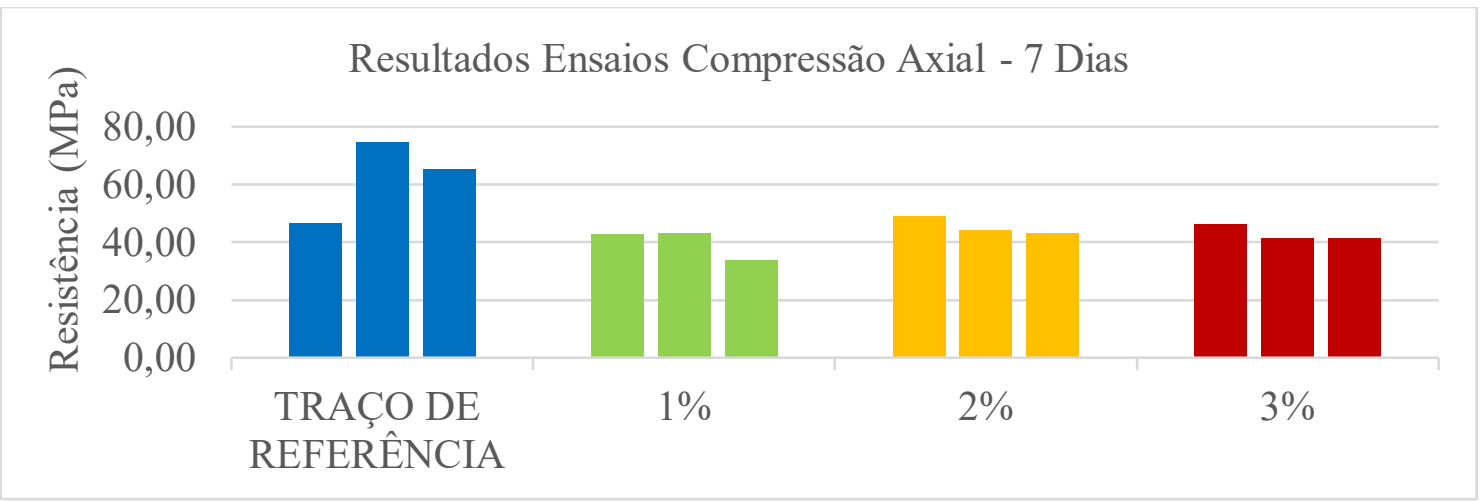

Figura 7 - Gráfico dos Resultados Ensaios de Compressão Axial

No gráfico da Figura 8 elaborou-se uma análise através da dispersão de pontos contendo uma linha de tendência correspondente a média corrigida descartando os valores discrepantes que não correspondiam aos limites inferiores e superiores definidos.

O gráfico demonstra uma tendência de queda de resistência com o incremento de fibras. Observase que seria interessante utilizar maiores percentuais de fibra para confirmar essa tendência de queda ou a formação de uma linha assintótica.

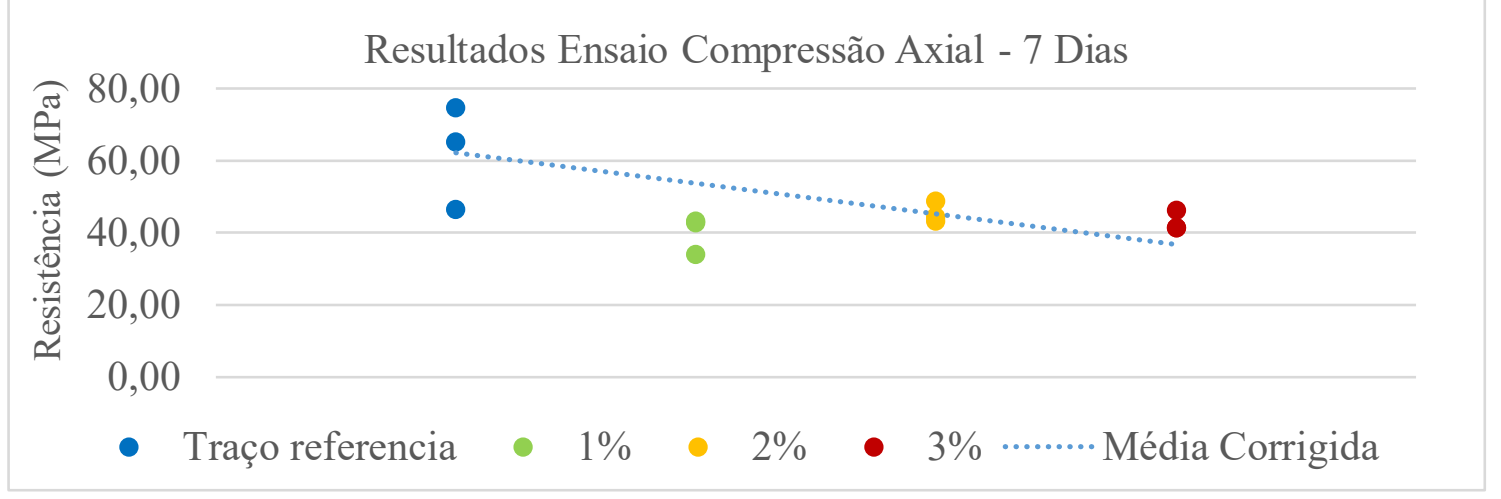

Figura 8 - Gráfico dos Resultados Ensaios de Compressão Axial - Média Corrigida

Aos 28 dias o mesmo teste foi realizado e com os resultados foi gerado a Tabela 6 . 
Tabela 5- Resistência a Compressão aos 28 dias

\begin{tabular}{|c|c|c|c|c|c|c|c|c|c|}
\hline \multicolumn{10}{|c|}{ COMPRESSÃO AXIAL - 28 DIAS } \\
\hline & \multicolumn{2}{|c|}{ RESISTÊNCIA (Mpa) } & MÉDIA & $\begin{array}{c}\text { DESVIO } \\
\text { PADRÃO }\end{array}$ & LIM SUP & LIM INF & MED COR & $\begin{array}{c}\text { DIFERENÇA } \\
\text { PERCENTUAL }\end{array}$ \\
\hline $\begin{array}{c}\text { TRAÇO DE } \\
\text { REFERÊNCIA }\end{array}$ & 50,96 & 41,40 & 50,96 & 50,96 & 4,25 & 55,20 & 46,71 & 50,96 & \\
\hline $\mathbf{1 \%}$ & 60,87 & 65,82 & 64,33 & 64,33 & 1,87 & 66,20 & 62,46 & 65,08 & $-28 \%$ \\
\hline $\mathbf{2 \%}$ & 52,81 & 63,02 & 35,94 & 52,81 & 9,77 & 62,58 & 43,04 & 52,81 & $-4 \%$ \\
\hline $\mathbf{3 \%}$ & 37,02 & 31,19 & 23,51 & 31,19 & 4,71 & 35,90 & 26,48 & 31,19 & $39 \%$ \\
\hline
\end{tabular}

Através dos resultados obtidos no ensaio, verificou-se que os concretos dos CP's com adição de fibras tiveram um ganho na resistência à compressão axial em relação ao traço de referência para adições contidas nos intervalos de baixa e moderadas frações volumétricas de $1 \%$ e $2 \%$ e uma queda para adição de alta fração volumétrica $3 \%$.

Sendo assim, o ensaio de compressão axial aos 28 dias obteve-se para o concreto para as diferentes frações volumétricas de fibras de polipropileno uma diferença percentual na resistência de:

- Diferença Percentual de -28\%: Baixa fração volumétrica (1\%);

- Diferença Percentual de -4\%: Moderada Fração Volumétrica (2\%);

- Diferença Percentual de 39\%: Alta Fração Volumétrica (3\%).

O gráfico da Figura 9 apresenta os resultados da Tabela 7, para todos os corpos de prova ensaiados. Já ao gráfico da Figura 10, mostra a dispersão de pontos contendo uma linha de tendência correspondente a média corrigida descartando os valores discrepantes que não correspondiam aos limites inferiores e superiores definidos. O gráfico demonstra uma tendência de queda de resistência com o incremento de fibras. Observa-se que seria interessante utilizar maiores percentuais de fibra para confirmar essa tendência de queda ou a formação de uma linha assintótica.

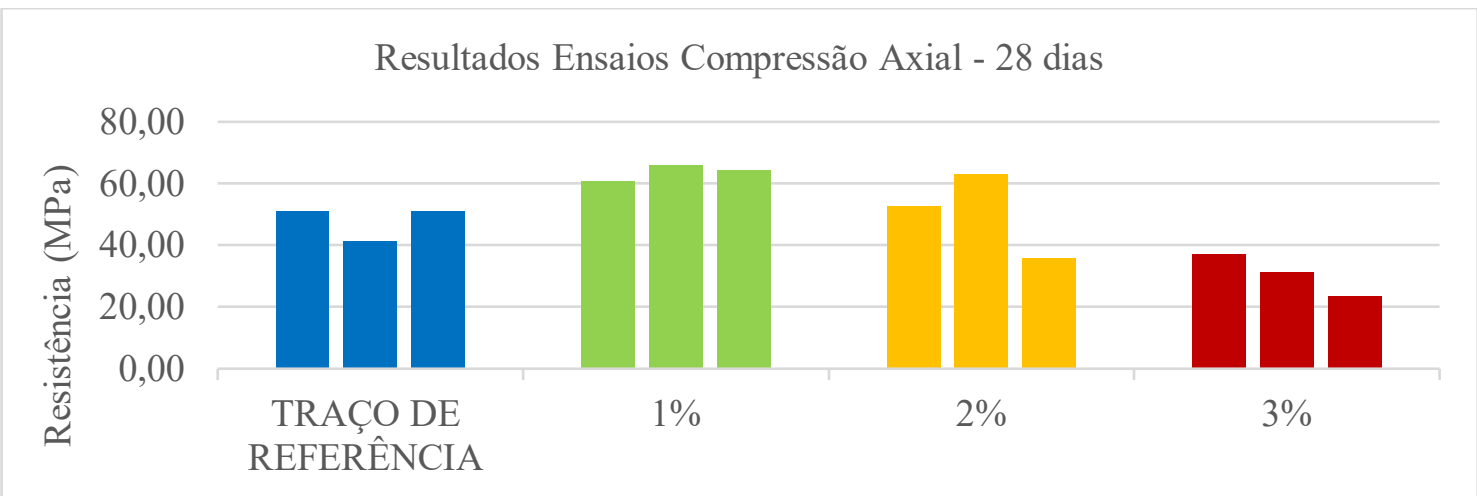

Figura 9 - Gráfico dos Resultados Ensaios de Compressão Axial - 28 Dias 
Resultados Ensaio Compressão Axial - 28 dias

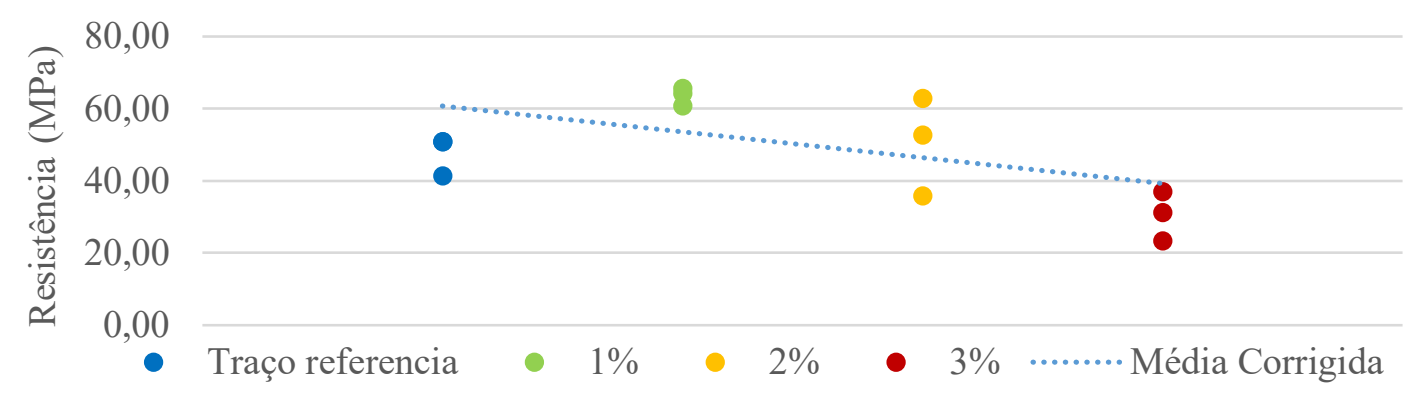

Figura 10 - Gráfico dos Resultados Ensaios de Compressão Axial - Média Corrigida

A partir dos resultados obtidos para 7 e 28 dias, foi elaborado o gráfico apresentado na Figura 11 fazendo uma análise comparativa entre estes resultados.

Compressão 7 dias x Compressão 28 dias

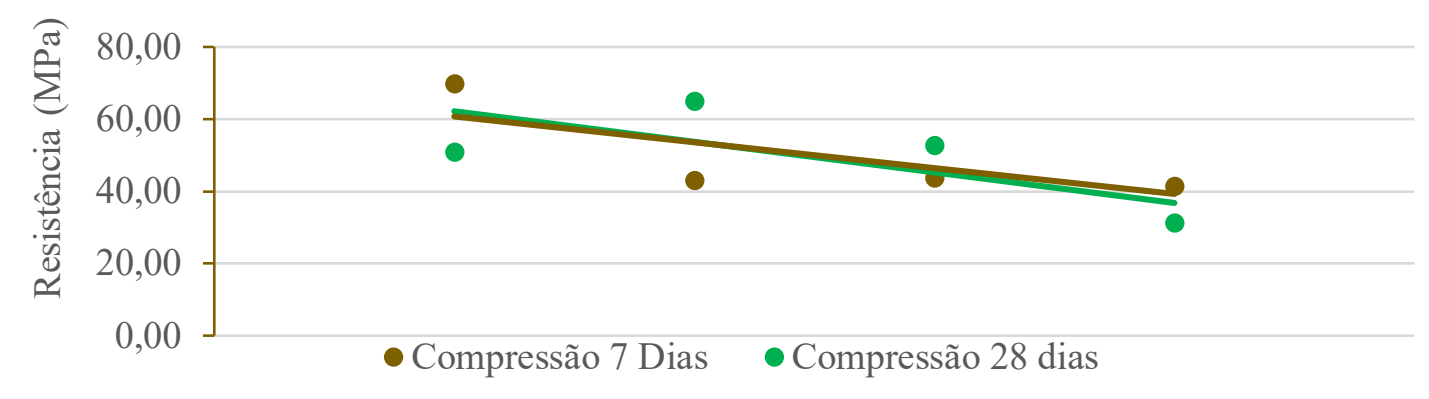

Figura 11 - Gráfico dos Resultados Ensaios de Compressão x Compressão - 7 e 28 Dias

Comparando as duas curvas observa-se que a queda de resistência foi similar, mostrando que a influência do percentual de fibra não depende do tempo em dias.

\subsection{Compressão Diametral (Tração Indireta)}

Os ensaios de compressão diametral foram realizados na Prensa Hidráulica Amsler na escala de I$40 \times 1000 \mathrm{kgf}=40$, seguindo o que prescreve a norma NBR 7222/2011.

Infelizmente não foi possível realizar o ensaio de compressão diametral para o traço de referência em função da perda dos corpos de prova. Com isso optou-se por utilizar o valor de $10 \%$ da resistência à compressão, como é prescrito na NBR 6118:2014. A Tabela 7 apresenta os resultados obtidos.

Tabela 6- Resistência a Tração a 7 dias

\begin{tabular}{|c|c|c|c|c|c|c|c|c|c|}
\hline \multicolumn{10}{|c|}{ TRAÇÃO 7 DIAS } \\
\hline & \multicolumn{10}{|c|}{ RESISTÊNCIA (Mpa) } & MÉDIA & $\begin{array}{c}\text { DESVIO } \\
\text { PADRÃO }\end{array}$ & LIM SUP & LIM INF MED COR & $\begin{array}{c}\text { DIFERENÇA } \\
\text { PERCENTUAL }\end{array}$ \\
\hline $\begin{array}{c}\text { TRAÇO DE } \\
\text { REFERÊNCIA }\end{array}$ & 4,65 & 7,45 & 6,52 & 6,52 & 1,04 & 7,56 & 5,48 & 6,98 & \\
\hline $\mathbf{1 \%}$ & 3,50 & 5,84 & 4,25 & 4,25 & 0,87 & 5,12 & 3,38 & 5,05 & $28 \%$ \\
\hline $\mathbf{2 \%}$ & 3,37 & 4,65 & 4,78 & 4,65 & 0,60 & 5,25 & 4,05 & 4,72 & $32 \%$ \\
\hline $\mathbf{3} \%$ & 3,75 & 5,40 & 4,65 & 4,65 & 0,57 & 5,22 & 4,08 & 4,65 & $33 \%$ \\
\hline
\end{tabular}


Por meio dos resultados obtidos no ensaio, verificou-se que os concretos dos CP's com adição de fibras tiveram uma queda na resistência à tração em relação ao traço de referência para ambas as frações volumétricas adicionadas. Ademais, como obteve-se os resultados através do método indireto por compressão diametral é justificável que essa tendência e/ou comportamento sejam proporcionais. Sendo assim, o ensaio de tração aos 7 dias obteve-se uma diferença percentual na resistência de:

- Diferença Percentual de 28\%: Baixa fração volumétrica (1\%);

- Diferença Percentual de 32\%: Moderada Fração Volumétrica (2\%);

- Diferença Percentual de 33\%: Alta Fração Volumétrica (3\%).

Os dados apresentados na Tabela 7 foram representados na Figura 13 e Figura 14. Observa-se que houve uma queda menos acentuada do que o resultado da compressão axial. Esse comportamento demonstra a relevância da adição de fibra para este ensaio.

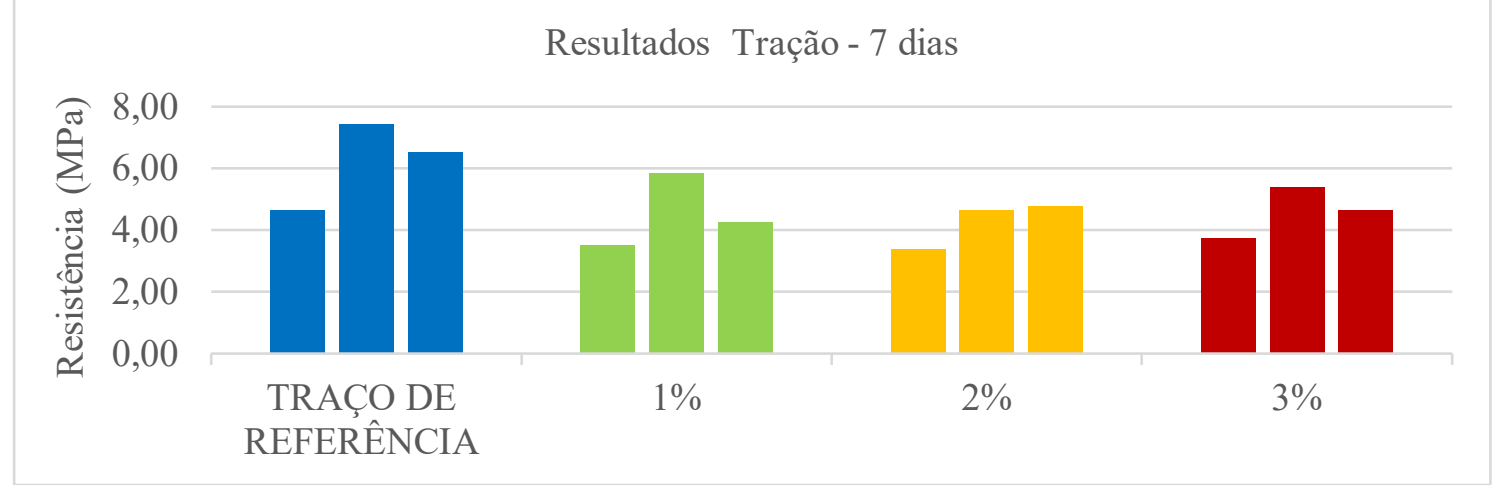

Figura 12 - Gráfico dos Resultados Ensaios de Tração - 7 Dias

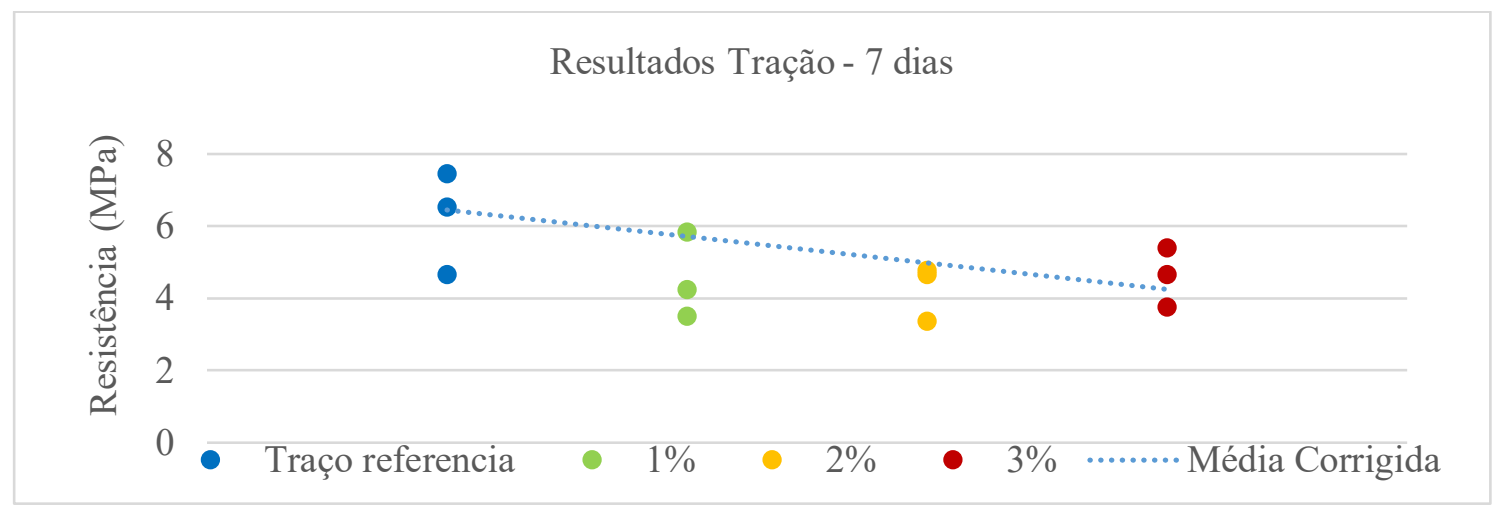

Figura 13 - Gráfico dos Resultados Ensaios de Tração - Média Corrigida

Tabela 7- Resistência a Tração aos 28 dias

\begin{tabular}{|c|c|c|c|c|c|c|c|c|c|}
\hline \multicolumn{10}{|c|}{ TRAÇÃO - 28 DIAS } \\
\hline & \multicolumn{2}{|c|}{ RESISTÊNCIA (Mpa) } & MÉDIA & $\begin{array}{c}\text { DESVIO } \\
\text { PADRÃO }\end{array}$ & LIM SUP & LIM INF MED COR & $\begin{array}{c}\text { DIFERENÇA } \\
\text { PERCENTUAL }\end{array}$ \\
\hline $\begin{array}{c}\text { TRAÇO DE } \\
\text { REFERÊNCIA }\end{array}$ & 5,10 & 4,14 & 5,10 & 5,10 & 0,42 & 5,52 & 4,67 & 5,10 & \\
\hline $\mathbf{1 \%}$ & 6,32 & 6,20 & 3,11 & 6,20 & 1,40 & 7,60 & 4,80 & 6,26 & $-23 \%$ \\
\hline $\mathbf{2 \%}$ & 4,93 & 5,14 & 1,93 & 4,93 & 1,38 & 6,31 & 3,55 & 5,04 & $1 \%$ \\
\hline $\mathbf{3 \%}$ & 4,37 & 3,90 & 4,08 & 4,08 & 0,17 & 4,25 & 3,91 & 4,08 & $20 \%$ \\
\hline
\end{tabular}


Através dos resultados obtidos no ensaio, verificou-se que os concretos dos CP's com adição de fibras tiveram um ganho na resistência à tração em relação ao traço de referência para adição de baixa fração volumétrica de $1 \%$ e uma queda para adições de média e alta fração volumétrica $2 \%$ e 3\% respectivamente. Ademais, como obteve-se os resultados através do método indireto por compressão diametral é justificável que essa tendência e/ou comportamento sejam proporcionais. Sendo assim, o ensaio de tração aos 28 dias obteve-se uma diferença percentual na resistência de:

- Diferença Percentual de -23\%: Baixa fração volumétrica (1\%);

- Diferença Percentual de 1\%: Moderada Fração Volumétrica (2\%);

- Diferença Percentual de 20\%: Alta Fração Volumétrica (3\%).

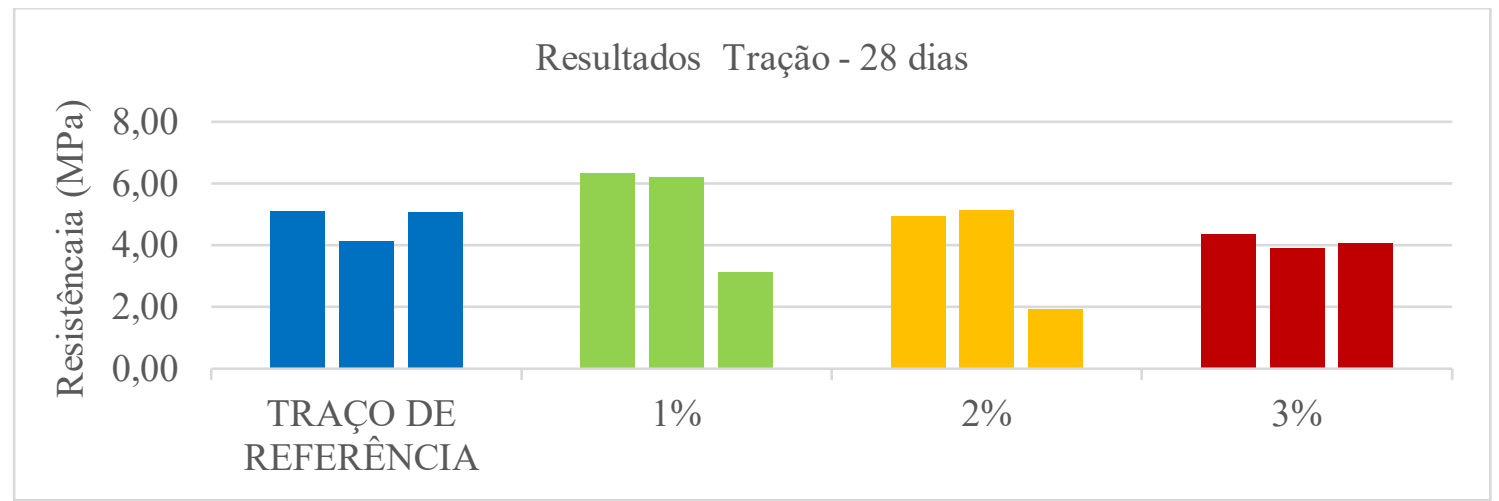

Figura 14 - Gráfico dos Resultados Ensaios de Tração - 28 Dias

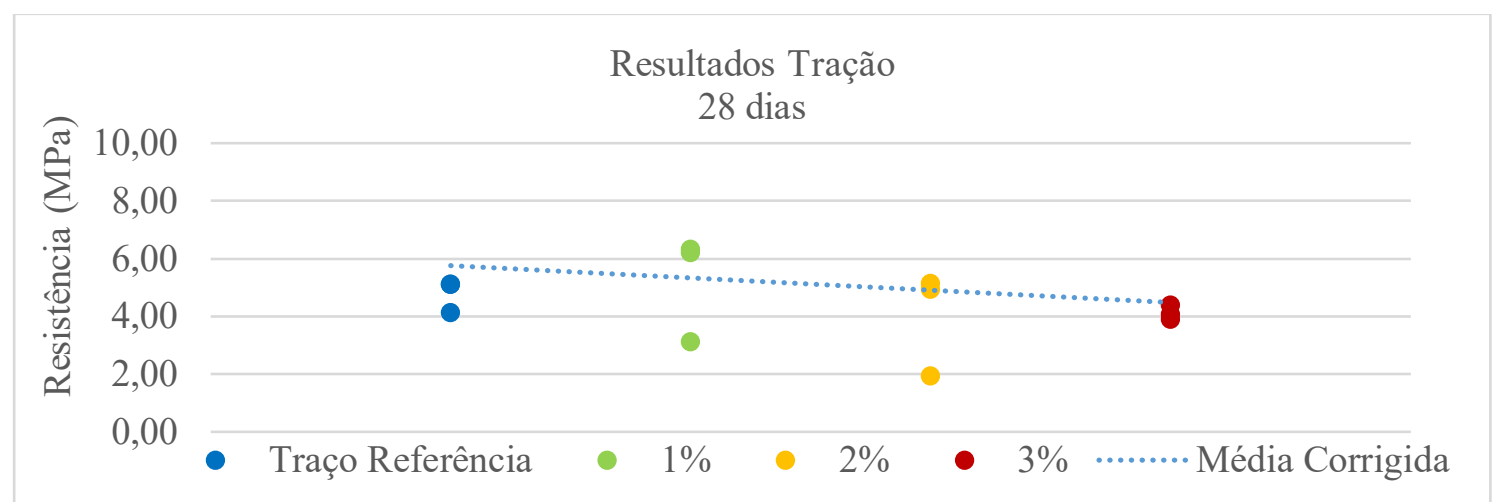

Figura 15 - Gráfico dos Resultados Ensaios de Tração - 28 Dias 
A partir dos resultados obtidos para 7 e 28 dias, foi elaborado o gráfico apresentado na Figura 17 fazendo uma análise comparativa entre estes resultados.

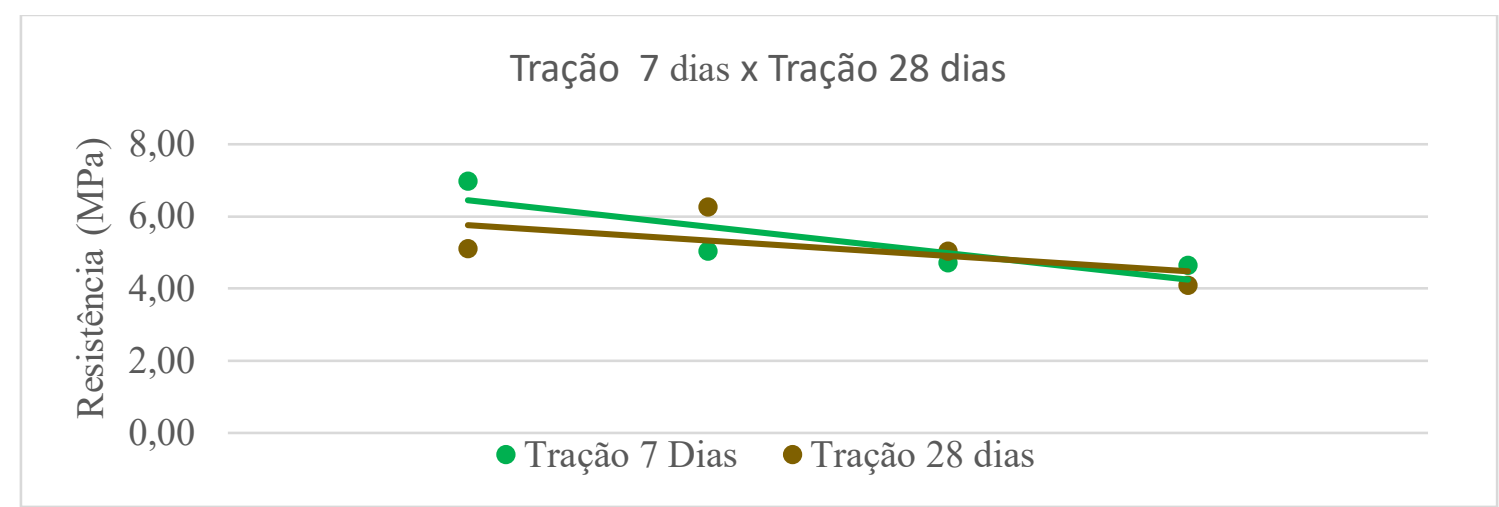

Figura 16 - Gráfico dos Resultados Ensaios de Tração x Tração - 7 e 28 Dias

Comparando as duas curvas observa-se que a queda de resistência foi similar, mostrando que a influência do percentual de fibra não depende do tempo em dias.

\section{CONCLUSÕES}

Dentro do contexto do CRF, a fibra adicionada ao composto gera alterações nas propriedades mecânicas do concreto, ela atua como uma ponte de tensão, transferindo os esforços mobilizadas no concreto fissurado evitando que eles se concentrem na extremidade da fissura adotando um comportamento pseudo-dúctil. Além da sua capacidade de absorção de energia do concreto, retardando o momento da ruptura, suportando tensões e deformações maiores que o concreto convencional após atingir a tensão máxima uma vez que consomem mais energia até a ruptura, enquanto que na questão do volume de fibras adicionadas elas alteram na trabalhabilidade da mistura por aumentar a área superficial do concreto, pois a demanda de água é aumentada apesar da fibra não absorver o líquido ela forma uma película em toda sua superfície, provocando um acréscimo na coesão e na perda da trabalhabilidade do concreto no estado fresco.

Apesar de todas as propriedades que a fibra pode alterar ao ser adicionado no concreto existe apenas uma única referência normativa brasileira com enfoque a fibras, a NBR 1530:2019 que estabelece parâmetros de classificação para as fibras de aço de baixo teor de carbono e dispõe sobre os requisitos mínimos de forma geométrica, tolerâncias dimensionais, defeitos de fabricação, resistência à tração e dobramento. Enquanto que para as fibras de polipropileno não há nenhuma norma técnica a ser utilizada, demonstrando que esse assunto deve ser melhor regulamentado para maior difusão.

Através dos ensaios realizados pôde-se constatar que a fibra de polipropileno, apresentou uma redução na resistência à compressão quando comparado a resistência à compressão do concreto com o traço de referência. Essa redução deve ser melhor avaliada com o ensaio de um maior número de corpos de provas. Em contrapartida, os resultados para tração mostram um acréscimo na capacidade do concreto em resistir as tensões de tração. Isso corrobora com o que está disponibilizado na literatura. Foi constatado que os corpos de prova com adição de fibras em volume de 2 e 3\% apresentaram maior segregação em relação ao traço de 1\%. Esse resultado já era esperado visto que a trabalhabilidade do concreto é função do volume de fibra adicionado. 


\section{REFERÊNCIAS}

Associação Brasileira de Normas Técnicas. (2015). NBR 5738: Concreto - procedimento para moldagem e cura de corpos de prova. Rio de Janeiro.

Associação Brasileira de Normas Técnicas. (2018). NBR 5739: Concreto - ensaio de compressão de corpos-de-prova cilíndricos. Rio de Janeiro.

Associação Brasileira de Normas Técnicas. (2011). NBR 7222: Argamassa e concreto: determinação da resistência à tração por compressão diametral de corpos-de-prova cilíndricos. Rio de Janeiro.

Associação Brasileira De Normas Técnicas. (1996) NBR NM 67: Concreto - Determinação da consistência pelo abatimento do tronco de cone. Rio de Janeiro.

FIGUEIREDO, A. "Concreto reforçado com fibras"( 2011). Tese (Livre Docência) - Escola Politécnica da Universidade de São Paulo. Acesso em: 16 abr. 2021. https://teses.usp.br/teses/disponiveis/livredocencia/3/tde-18052012-112833/pt-br.php

MEDEIROS, A (2012). "Study of the compressive fatigue behavior of fiber reinforced concrete", D.Sc.Thesis, Pontificia Universidade Católica do Rio de Janeiro,201p http://bdtd.ibict.br/vufind/Record/PUC_RIO-1_260259f293309a394395939db301cb4a . Acesso em: 10 maio. 2021. 